\title{
A Look Inside
}

Standard neurobiology textbooks commonly do not contain a chapter on cancer, and the word might not even appear in the index. Its absence cannot be explained simply on the grounds that the subject falls more appropriately within the clinical realm, because you will find chapters devoted to various other nervous system diseases. Could this intellectual blind spot result from the fact that mature neurons, being post-mitotic, do not succumb to the disease? This absence in most texts is curious, considering the severe functional implications. The word is sometimes used metaphorically to connote an unstoppable process of destruction, and indeed some forms of brain cancer present the most dire prognosis of any cancer. But more importantly the neglect of this subject is curious, because on a molecular and cellular level, cancer is the result of biological processes that are at the forefront of modern neurobiological research. These include such current hot-topic areas as intraand inter-cellular signaling networks, regulation of gene transcription, control of cellular differentiation, regulation of cell motility, migration and cell death; the secretion and response to growth factors, and interactions with the vascular and immune systems. Finally, the current enthusiasm and promising research on the use of stem cells for therapeutic treatment of nervous system disease has brought us face-to-face with our ignorance in this area, as we find that many types of stem cells transplanted into the brain form tumors. This issue of Neuron Glia Biology contains a special collection of original research papers on cancer in the peripheral and central nervous system and a review on the subject. These papers are introduced below by Special Feature Editor, Philip Lee.

The recent passing of Francis Crick, a scientist who transformed biological research in the twentieth century and devoted his life to neurobiology after his unparalleled achievements in molecular biology, reminds us of how much neurobiological research has been changed by the advances in molecular biology. But in an age when it is possible to make a mouse of endless genetic variety, the experimental approach recognizing that Nature has been doing so much longer - and not just with mice - has become less traveled. The essay by Dr. Theodore Bullock, on A natural history of neuroglia, provides a thought-provoking review of the literature available on glia in vertebrate and invertebrate nervous systems, which makes a compelling argument for greater research in comparative studies of glia in non-mammalian organisms. Many will be surprised to learn that the fastest conduction velocity is not found in the myelinated axon of a mammal, but in the axon of an invertebrate; or that increasing the axon diameter is not the only, or the best way invertebrates have evolved to increase conduction velocity. There is little doubt that understanding the various mechanisms that have evolved in invertebrates to provide rapid impulse conduction in the absence of myelin would expand our understanding of neuron-glia interactions in vertebrates and suggest potential new avenues for coping with demyelinating diseases in humans.

Genetic manipulation of the robo and $\mathrm{gcm}$ genes in the fruit fly has enabled Kinrade and Hidalgo to investigate mechanisms that guide axons during nervous-system development. Their results show that glia are essential in this process and that neuron-glia interactions steer the response of axons to the 'Robo code'.

The study by Lepore et al., concerns the topical issue, mentioned above, of transplanting stem cells into the brain for therapeutic treatment, and specifically, the important issue of determining the most optimal stage of cell differentiation for transplantation. Their findings indicate that transplants of lineage-restricted neuronal or glial precursors from the spinal cord survive and differentiate better when grafted into the adult brain than do multipotent neuroepithelial stem cells.

R. Douglas Fields Editor, Neuron Glia Biology

\section{Special Feature Section on Nervous System Cancer}

A thoughtful review on the topic of neural development and tumorigenesis by Scott L. Pomeroy opens the Special Feature section. This review focuses on the current state of neuro-oncology research, and places it in the context of our understanding of normal brain development.

Moving into the PNS, we have two papers on the topic of Neurofibromatosis type 1. Lee et al. have performed a largescale microarray screen, revealing wide deregulation of genes in an MPNST cell line derived from an NF1 patient. Deadwyler et al. present a study implicating activation of prostaglandin metabolism as a possible contributor to tumor growth in NF1.
To finish the Special Feature section we move back into the CNS. In the study by Lassman et al., it is shown that overexpression of c-Myc oncogene promotes dedifferentiation of GFAP expressing astrocytes, thereby making these cells susceptible to transformation by Ras and Akt.

Finally, Gondi et al. present an extensive study using RNAi to silence three regulatory protease genes, which are highly expressed in human gliomas. This results in marked decreases in invasive, angigenic and tumorigenic properties. 


\section{REFERENCES}

Bullock, T.H. (2004) The natural history of neuroglia: an agenda for comparative studies. Neuron Glia Biology 1, 97-100.

Deadwyler, G.D., Dang, I., Nelson, J., Srikanth, M. and DeVries, G.H. (2004) Prostaglandin E2 metabolism is activated in Schwann cell lines derived from human NF1 malignant peripheral nerve sheath tumors. Neuron Glia Biology 1, 149-155.

Gondi, C.S., Lakka, S.S., Dinh, D.H., Olivero, W.C., Gujrati, M. and Rao, J.S. (2004) Downregulation of uPA, uPAR and MMP-9 using small, interfering, hairpin RNA (siRNA) inhibits glioma cell invasion, angiogenesis and tumor growth. Neuron Glia Biology 1, 165-176.

Kinrade, E.F.V. and Hidalgo, A. (2004) Lateral neuron-glia interactions steer the response of axons to the Robo code. Neuron Glia Biology 1, $101-112$.
Lassman, A.B., Dai, G.N., Vickers, A.J. and Holland, E.C. (2004) Overexpression of c-Myc promotes an undifferentiated phenotype in cultured astrocytes and allows elevated Ras and Akt signaling to induce gliomas from GFAP-expressing cells in mice. Neuron Glia Biology 1, 157-163.

Lee, P.R., Cohen, J.E., Tendi, E.A., Farrer, R., DeVries, G.H., Becker, K. G. and Fields, R.D. (2004) Transcriptional profiling in an MPNSTderived cell line and normal human Schwann cells. Neuron Glia Biology 1, 135-147.

Lepore, A.C., Han, S.S.W., Tyler-Polsz, C.J., Cai, J., Rao, M.S. and Fischer, I. (2004) Differential fate of multipotent and lineagerestricted neural precursors following transplantation into the adult CNS. Neuron Glia Biology 1, 113-126.

Pomeroy, S.L. (2004) Neural development and the ontogeny of central nervous system tumors. Neuron Glia Biology 1, 127-133. 